\title{
Tendon Healing with Growth Factors
}

\author{
Sebastian Müller, Atanas Todorov, \\ Patricia Heisterbach and Martin Majewski \\ University of Basel, \\ Department of Orthopaedic Surgery and Traumatology \\ Switzerland
}

\section{Introduction}

The incidence of sport injuries has increased in recent years due to fitness training and growing participation in sport activities by the general public. The tendon rupture was regarded as an injury typical of high-performance athletes. As physical and recreational activities become more and more popular followed by an increased frequency of soft tissue injuries, health care costs are raising. Tendon lacerations, ruptures, or inflammation cause marked morbidity and has a major impact on work, recreational activities, and daily needs. Tendon ruptures and tears are slow healing injuries that are often treated surgically with unsatisfactory results for some patients. As biology of healing processes and the influence of growth factors are becoming more and more clear, one can consider introducing biological therapy into clinical use. For optimizing treatment more understanding is needed. Therefore tendon physiology, pathology, ruptures biology and functionality, normal healing process, as well as the role of polypeptide factors during healing need to be known.

The injury itself initiates several pathways of signalling that recruits fibroblasts and stimulates tenocytes for collagen synthesis and other extracellular components. Together with some mechanical stress, the healing process is able to restore tendon tissue partially or sometimes close-to-normal. However, repaired tendon tissue rarely achieves functional normal tendon. To improve such results, this complex process requires a combination of treatments as: non-operative or operative treatment to restore length, early functional therapy for mechanical stimulation, and tissue engineering to provide additional growth factors.

These treatment modalities may improve tissue healing, tendon gliding, mechanical strength, and return to normal function while preventing tendon gapping, ruptures, and extensive adhesions. Recent advances in bioengineering including the use of growth factors, mesenchymal stem cells and biocompatible scaffolds are promising.

Although the effect of growth factors on tendon healing is impressive, it has become increasingly clear that tendon repair is not triggered by a single growth factor but requires the interplay of various such factors. Collectively, they exert powerful and comprehensive effects on healing. Therefore further research is needed. 


\section{Tendon structure and healing}

\subsection{Tendon structure}

Tendons functionally connect the dynamic and static components of the locomotive apparatus. Disturbances in the propagation of force from muscle to bone are associated with a considerable loss of function of the extremity. In order to fulfill these functions tendons have special morphological characteristics: fibers are closely packed in a parallel arrangement. The high collagen content and the parallel orientation of the fibers give them extraordinary tensile strength, the highest of any tissue in the body. This characteristic results, for the most part, from the composition and structure of the collagen and elastic fibers, and their interplay. Collagen accounts for $70 \%$ of the dry weight of tendons, $95 \%$ of which is collagen type I and to a smaller extent elastin (Birk \& Trelstad, 1984; Molloy et al., 2003). The remaining 5\% is composed of collagen type III as well as a glycosaminoglycan component of approximately 0.5\% (Ducy \& Karsenty, 2003; Gerich et al., 1996). Collagen is rich in proline and glycine and contains hydroxyproline and hydroxylysine. Lysine and proline residues get hydroxylated within fibroblasts. Hydroxyproline and hydroxylysine are important in maintaining tendon structure; they form $\mathrm{H}$-bridges and hydroxylysine residues are involved in the covalent cross-linking of collagen fibers (Molloy et al., 2003). The individual collagen fibers are arranged in fascicles that contain nerve fibers, blood and lymph vessels (Petersen et al., 2003a; Petersen et al., 2004). Within the fascicles there exist specialized fibroblasts called tenocytes, which exhibit a high degree of organization. Vertically they appear star-like and longitudinally they appear to be arranged in a row along the fibers. This special orientation of the cells reflects their function. These cells are capable of synthesizing fibrillose as well as non-fibrillar components of the extracellular matrix and can also resorb collagen fibers (Chan et al., 1997; Gerich et al., 1996). The fascicles are covered with epitenon, which in turn is covered with paratenon. A fluid film lies between these two layers, which make the movements of the tendon possible.

\subsection{Tendon healing}

Study of the physiology of tendon healing has revealed two mechanisms of healing, intrinsic and extrinsic healing (Grotendorst, 1988; Hefti \& Stoll 1995). During intrinsic healing the tendon with the surrounding tendon sheath are obliterated. The healing of defects between the tendon ends consists of an exudative and a formative phase which are for the most part similar to wound healing in other parts of the body (Maffulli et al., 2000). The concept of extrinsic tendon healing is based on the fact that the cells responsible for the process migrate from the peripheral tendon sheath to the area of the defect (Özkan et al., 1999). This was seen in animal experiments, where fibroblasts and newly formed collagen fibers in the first days after the injury were arranged in a radial manner and then after several days oriented in a longitudinal fashion according to the stress load profile of the tendon. It is now assumed that both extrinsic and intrinsic tendon healing play important roles. Tendon healing can be summarized as follows (Gerich et al., 1996).

\subsection{The three phases of tendon healing}

Tendon healing occurs in three phases, an inflammatory, a repair, and a remodeling phase (Lou et al., 1996). The inflammatory phase occurs during the first three to five days after 
injury. It is characterized by the migration and proliferation of cells from the extrinsic peritendonal tissue such as the paratenon, subcutaneous fat tissue and fascia and the intrinsic epitenon and endotenon (Party et al., 1978). At first the extrinsic tissue repair predominates. In this manner the tissue defect is filled with granulation tissue of extrinsic origin. The fibroblasts, which migrate into the area of the injury, have phagocytic properties and at first are found in a radiating pattern along the length of the tendon. During this inflammatory phase the defect zone is filled with tissue that includes parts of the ruptured tendon and hematoma and the biomechanical stability is dependent on the fibrin fibers (Lou et al., 1996).

Around the fifth day the fibroblasts, which have migrated into the wound area, start to synthesize collagen. Initially there is no uniform orientation of the newly formed collagen fibers. They contribute to a great degree to the biomechanical stability of the defect zone. Fibroblasts are the dominant cell type within the lesion and the collagen component increases continuously until the fifth week.

In the fourth week increased proliferation of fibroblasts of intrinsic origin occurs. These fibroblasts are mostly derived from the endotenon and actively remodel collagen. As tissue maturation proceeds collagen fibers increasingly orient themselves along the functional stress axis of the tendon. This reparative phase takes place approximately two months after injury.

\begin{tabular}{l|ll}
$\begin{array}{l}\text { Time } \\
\text { (days) }\end{array}$ & Phase & Process \\
\hline 0 & $\begin{array}{l}\text { Immediately post- } \\
\text { injury }\end{array}$ & Clot formation around the wound \\
$0-1$ & Inflammatory & $\begin{array}{l}\text { First battery of growth factors and inflammatory } \\
\text { molecules produced by cells within the blood clot }\end{array}$ \\
$1-2$ & Proliferation & $\begin{array}{l}\text { Invasion by extrinsic cells, phagocytosis } \\
\text { Further invasion by extrinsic cells, followed by a } \\
\text { second battery of growth factors that stimulate } \\
\text { fibroblast proliferation }\end{array}$ \\
$4-4$ & Reparative & $\begin{array}{l}\text { Collagen deposition; granulation tissue formation; } \\
\text { revascularisation } \\
\text { Injury site becomes more organised; extracellular } \\
\text { matrix is produced in large amounts }\end{array}$ \\
$7-14$ & Remodelling & $\begin{array}{l}\text { Decreases in cellular and vascular content; increases } \\
\text { in collagen type I } \\
\text { Collagen continues to become more organised and } \\
\text { cross-linked with healthy matrix outside the injury } \\
\text { area. Collagen ratios, water content and cellularity } \\
\text { begin to approach normal levels }\end{array}$ \\
& &
\end{tabular}

Table 1. Summary of the healing process in tendons and ligaments. From Molloy et al., 2003. 
Final biomechanical stability is achieved in response to resuming normal movement. During this period further organization of the collagen fibers along the stress axis of the tendon occurs. In addition, tensile strength is increased through cross-linking between the collagen fibrils. There is a shift from the synthesis of type III collagen to the mechanically more stable type I collagen (Möller et al., 1998; Pierce et al., 1995). There is no complete regeneration of the tendon lesion in spite of the intensive remodeling in the initial months after injury. The repaired tissue remains hypercellular and there is a shift in favor of thinner collagen fibrils, which compromises its biomechanical characteristics (Maffulli et al., 2002; Möller et al., 1998). In the flexor tendon, an increased production of type III collagen is seen up to 14 months after injury (Pierce et al., 1995). These results are mirrored in a reduced collagen fibrillar diameter, which is seen after tendon injury (Janqueira et al., 1978; Möller et al., 1998). The concentration of collagen type III with this type of regenerate is inversely proportional with the mechanical resilience of the healed tendon (Laemmli, 1970).

Collagen type analyses performed after Achilles tendon rupture indicate a decrease in collagen type I alongside a significant increase in the amount of collagen type III (Ducy \& Karsenty, 2003). An elevation of the amount of collagen type III is thought to be the cause of reduced tensile strength in connective tissue due to the reduced cross-linking of this collagen type (Janqueira et al., 1978, Jozsa et al., 1984; Lou et al., 1997, Maffulli et al. 2002). This phenomenon is involved in the pathogenesis of degenerative tendinopathies such as with achillodynia and degenerative rotator cuff lesions (Lou et al., 1997). The development of hypertrophic, biomechanical inferior, replacement tissue is caused by recurrent microtrauma.

\subsection{Influence of growth factors}

Cellular growth factors and cytokines play key roles during embryonic tissue differentiation and during wound healing (Gabra et al, 1994; Goomer et al. 2000; Grotendorst et al., 1985; Hudson-Goodman et al., 1990; Mason \& Allen 1941). Growth factors are known to stimulate cell differentiation, chemotaxis, angiogenesis, and extracellular cell matrix synthesis (Mason \& Allen 1941; Nakamura et al., 1996; Nakamura et al., 1998). Furthermore, these factors regulate cellular synthesis and the secretion activity from matrix components and influence in this manner the course and results of would-healing (Gabra et al., 1994; Lou et al., 1997). The diversity of the cytokinetic characteristics lends credence to the concept that these growth factors are potentially capable of modulating the tendon healing processes, resulting in better healing (Mason \& Allen 1941).

The influence of growth factors on tendon healing has been investigated through comparative studies of the profiles of cytokines of injured and normal tendons. It has been shown that wounding and inflammation provoke release of growth factors (Nakamura et al., 1996; Nakamura et al., 1998; Party et al 1978).

\subsubsection{PDGF}

However, healing tendons have increased PDGF-concentrations (Enzura et al., 1996; Nakamura et al., 1996; Nakamura et al., 1998). Under the influence of PDGF, rates of fibroblasts proliferation, chemotaxis and collagen synthesis are somewhat elevated (O'Brien $\mathrm{T}$, 1992). However, patellar tendon fibroblasts show higher proliferation after the addition of bFGF in vitro (Coombs et al., 1980) 
As Molloy wrote at his review, PDGF describes a group of dimeric polypeptide isoforms made up from three types of structurally similar subunits. Its activity is mediated through its interaction with two related tyrosine kinase receptors, one of which binds all three PDGF chains, and the other binds only one (Ronnstrand et al). Work by Duffy et al. (1995) has shown that PDGF is elevated in the healing canine digital flexor tendon, suggesting a role in the healing process. It is thought to play a significant role in the early stages of healing, at which time it induces the synthesis of other growth factors, such as IGF-I (Lynch et al, 1989). In vitro studies by Yoshikawa and Abrahamsson (2001) on PDGF have further demonstrated that this growth factor also plays an important role during tissue remodelling. PDGF was observed to stimulate both collagen and non-collagen protein production, as well as DNA synthesis, in a dose-dependent manner.

One theory that has been put forward as to how PDGF increases protein production involves its induction of TGF $\beta$-1 expression (Pierce et al., 1989). However, in vivo studies by Hildebrand et al. (1998) in which the PDGF isomer PDGF-BB was applied to the healing MCL of the rabbit with and without TGF $\beta-1$ showed no such complementary effect. In fact, addition of PDGF-BB and TGF $\beta-1$ together resulted in poorer healing (as determined by ultimate load, energy absorbed to failure, and ultimate elongation values) than addition of PDGF-BB alone. Stimulation of DNA synthesis by PDGF has also been postulated to occur through a growth factor second messenger. In this case, increases in PDGF have been shown to result in up-regulation of IGF-I and IGF receptors, that once activated stimulate DNA synthesis (Lymch et al 1989). A significant amount of the PDGF produced for this end is thought to come from an exogenous source, probably from platelets (Tsuzaki et al., 2000).

Interestingly, the level of stimulation has been shown to be specific to the site and type of tendon examined. In studies by Yoshikawa and Abrahamsson (2001) DNA synthesis was stimulated to higher levels in intermediate compared with intrasynovial tendons, and protein synthesis was higher in proxi- mal intrasynovial tendon segments than in extrasynovial peroneal tendon segments (Molloy et al, 2003).

\subsubsection{VEGF}

VEGF is required for the formation of the initial vascular plexus early in granulation tissue development and contributes to vascular bud formation and endotheliocyte migration during neo-vascularization, which occurs at the primary stage of tendon healing. However, his results suggest that VEGF deteriorated tendon properties via vessel formation and destruction of the collagen network while TGF- $\beta$ enhanced the tendon mechanical properties.

VEGF is not normally found in adult tendon, but is expressed in the healing tendon, alongside with increased expression of the VEGF receptors 1 and 2 in areas with great microvascular density (Petersen et al., 2003b)[18]. When added to a healing tendon, VEGF increases the vascularization from 1 to 8 weeks after rupture (Hou et al., 2009)[7]. Although the mechanical properties are better at 1 week, the difference is no longer significant after only 2 weeks (Zhang et al., 2003)[29]. Since prior to the formation of new vessels there is an increase of matrix metalloproteases and the vascular tissue has inferior mechanical properties compared to a tendon, this may explain the afore mentioned observation. Our findings suggest that VEGF is tightly controlled during at least 8 weeks in tendon healing 
without big increases or decreases in concentration, but possibly with a slight decrease up to 8 weeks. TGF- $\beta$ may exert some control over the expression of VEGF by depressing it (Hou et al., 2009)[7], but other pathways such as endostatin are also possible (Pufe et al., 2003)[20].

\subsubsection{TGF- $\beta$}

TGF- $\beta 1$ is known to play an important role in the healing process of injured tendon by directing the fibroblast migration (Roberts et al.,1988), neovascularization and secretion of extracellular matrix proteins like procollagen type I and III (Kashiwagi et al., 2004).

When TGF is added to the healing tendon, it has been shown to induce the expression of collagen I and III and also improve the mechanical properties of the tendon, seemingly accelerating the healing process (Hou et al., 2009; Kashiwagi et al., 2004). It may be that a single exposure to TGF- $\beta$ in sufficient dosage is already enough to mobilize and differentiate additional mesenchymal stem cells (Kashiwagi et al., 2004). Normally TGF- $\beta$ is expressed early in a healing tendon in the process of inflammation and reorganization at 4 and 7 days, whereafter the expression decreases at 2 and 4 weeks (Chan et al., 2003). Loading and mobilization of the tendon seem to decrease the expression of TGF- $\beta$ (Eliasson et al., 2009), possibly reducing the initial inflammation in the healing tendon. At the end stage of tendon healing TGF- $\beta$ may also promote the apoptosis of fibrocytes (Jorgensen et al., 2005; Lui et al., 2007). In our one studies we observe a high concentration of TGF- $\beta$ initially, which then decreased for 2 and 4 weeks and then increase massively at 8 weeks, possibly reflecting the initial inflammation and activation of cells, followed by an intermediary period and then the remodeling of the tendon with increased apoptosis of no longer necessary cells. The results are similar to those for the rat rotatory cuff (Würgler-Hauri et al., 2007), although we observe a steeper increase at 8 weeks.

\subsubsection{BMP-12}

Several BMPs are able to induce bone and cartilage formation in animals by influencing the differentiation of mesenchymal progenitor cells along the cartilage, or bone lineage (Ducy \& Karsenty, 2000; Wozney 1998). However, BMP-12, a human homologue of growth and differentiation factor 7 (GDF-7), does not induce bone or cartilage, BMP-12 induces the formation of tendon and ligament tissue (Enzura et al., 1996; Lou et al., 2001; Wolfman et al., 1997). Therefore, BMP-12 plays an important role in tendon healing. In order to optimize tendon healing it seems to be important to have a high level of expression of collagen type I. Corresponding to this fact there must also be a transition from the initial production of collagen type III to type I.

A natural course of BMP-12 expression has been measured in loaded rat achilles tendons although without the plantaris tendon to act as an internal splint which would mechanically stabilize the healing tendon in the early stages (Eliason et al., 2008). The resulting expression patterns have suggested an initially high expression of BMP-12 at the beginning of tendon healing at 3 days, followed by a decrease at 8 days even below the normal expression and up to 21 days a further slight decrease. At the same time loading of the healing tendon showed a decrease of the expression of follistatin, an inhibitor of BMP-12 (Eliason et al., 2008). Our data accordingly also shows an initially higher concentration of BMP-12 and subsequent decrease after 2 weeks. Because we have measured the concentration directly as 
opposed to the cellular expression, the time points are somewhat shifted, and it may be that the higher concentration of BMP-12 acts in a negative feedback loop to prevent further BMP12 expression. The effects of BMP-12 when added in a tendon healing model include the increase of tendon callus and the improvement of mechanical properties such as overall strength and stiffness, both after 1 week (Forslund et al., 2003; Majewski et al., 2008). However BMP-12 added during the first week of healing leads to a more organized tendon tissue (Murray et al., 2007), higher volumes of collagen I and an earlier shift of fibroblasts to fibrocytes (Majewski et al., 2008). Our results thus suggest a tightly controlled BMP-12 concentration, which possibly helps to coordinate the newly produced cells during proliferation in the early healing period. This is also seen with the rat rotatory cuff (WürglerHauri et al., 2007), yet we do not see an increase in concentrations after 8 weeks, again possibly reflecting the difference in both tendons.

\subsection{5 bFGF}

Use of bFGF in a healing tendon has been shown to increase cellularity early in the healing process (Chan et al., 2008). While reducing expression of collagen I and III in the first week (Thomopoulos et al., 2010), it increased both after two weeks (Sahoo et al, 2010), again suggesting a prolonged phase of proliferation, associated with a higher repair potential in a normally bradytrophic tissue. Extracellular matrix changes associated with bFGF are an increase of lubricants and matrix metalloproteases during the first week, supposedly creating the space needed for the additional tenoblasts and tenocytes (Thomopoulos et al., 2010). The initial increase in bFGF we have observed in our study may thus reflect an early phase of the healing process, which provides the tenocytes and fibroblasts needed for the repair of the extracellular matrix by stimulating their proliferation. This is in accordance with the study done in the rat rotatory cuff (Würgler-Hauri et al., 2007), but we have not observed the increase of bFGF after 8 weeks which possibly reflects one of the many differences of the achilles tendon and rotatory cuff.

\subsubsection{IGF}

During the initial repair process and the inflammatory phase, upregulation of growth factors and cytokines such as insulin-like growth factor-1 (IGF-1) stimulate the migration and proliferation of fibroblasts and inflammatory cells to the wound site (James et al., 2008; Kurtz et al., 1999; Tsuzaki et al., 2010). Several studies have shown that IGF-I is locally increased during and after inflammation following soft tissue injury, both at the mRNA and protein levels, and is associated with a corresponding up-regulation of its receptors (Bos et al., 2001; Edwall et al., 1989; Fortier et al.; 2001; Molloy et al., 2003; Rubini et al., 1994 Sciore et al., 1998; Tsuzaki et al., 2000; Vogt et al., 1998). James mentioned, that Insulin-like growth factor-1 may be stored as an inactive precursor protein in normal tendon and, upon injury, enzymes release the growth factor to exert its biological activity. During the later phases such as remodeling, IGF-1 stimulates synthesis of collagen and other extracellular matrix components; studies in vitro have shown that the effects of IGF-1 on matrix metabolism are dose dependent (James et al., 2008). As Molloy stated, its primary roles seem to be to stimulate the proliferation and migration of fibroblasts and other cells at the site of injury, and to subsequently increase the production of collagens and other extracellular matrix structures in these cells during the remodelling stages. Because IGF-I is such a versatile and 
widespread signal molecule, it has numerous and varied activities during tendon healing, particularly when working in concert with other growth factors. As with many other cytokines, synergism with other molecules is important for its stimulatory acivity. It is thought that IGF-I works to promote cell proliferation when in the presence of other growth factors, such as the PDGF isomer PDGF-BB (Molloy et al., 2003).

\begin{tabular}{|lll|}
\hline Repair phase & Activity & Growth Factor \\
\hline Inflammatory & Stimulates recruitment of fibroblasts and & IGF-1 \\
& inflammatory cells to the injury site & TGF- $\beta$ \\
& Regulation of cell migration & PDGF \\
& Expression and attraction of other growth factors (e.g. VEGF, bFGF \\
& IGF-1) & \\
& Angiogenesis & IGF-1, PDGF, TGF- $\beta$, \\
Proliferative & Cell proliferation (DNA synthesis) & bFGF, GDF-5,-6,-7 \\
& Stimulates synthesis of collagen and ECM & IGF-1, PDGF, bFGF \\
& components & TGF- $\beta$, bFGF \\
& Stimulates cell-matrix interactions & TGF- $\beta$, GDF-5,-6,-7 \\
\hline Collagen Type III synthesis & IGF-1 \\
\hline Remodelling & ECM remodelling & TGF- $\beta$ \\
& Termination of cell proliferation & TGF- $\beta$, GDF-5,-6,-7 \\
\hline
\end{tabular}

Table 2. Tendon repair phases with biological characteristics and ensuing molecular events that are regulated by several cytokines or growth factors (from James et al., 2008)

\subsubsection{Platelet-rich plasma}

Lately platelet-rich plasma is being progressively used to treat musculoskeletal conditions. Within their alpha granules and dense granules platelets have a rich store of factors and cytokines. Among others the alpha granules contain PDGF, TGF- $\beta$, IGF-1, VEGF, and EGF, whereas the dense granules contain neuromodulators and inflammatory modulators such as histamine and serotonin. By exposure to collagen, thrombin, or calcium platelets release these growth factors and cytokines (Fufa et al., 2008; Rodeo et al., 2010). For the treatment of chronic Achilles tendinopathy a randomized, double blind, placebo-controlled trial demonstrated no significant differences between patients managed with either platelet-rich plasma or saline solution injections (DeVos et al., 2010; Rodeo et al., 2010). In a prospective, randomized trial platelet-rich-fibrin-augmented rotator cuff repairs showed increased vascularization compared to the control group six but not twelve weeks postoperatively (Rodeo et al., 2010). Repaired superficial digital flexor tendons in front limbs of horses had a higher failure strength and greater elastic modulus 24 weeks postoperatively after being treated with platelet rich plasma compared to the control group with only saline injection. Histologically the platelet-rich plasma group demonstrated better collagen organization and increased metabolic activity (Bosch et al., 2010).

\subsubsection{Autologeous conditioned serum}

During our own studies on 80 male Sprague Dawley rats we found a marked increase of collagen type I and a decrease of collagen type III in animals treated with ACS (Majewski 
et al. 2009). An increased content of type III collagen in the fibers would tend to reduce their tensile strength (Jozsa et al, 1984; Jozsa et al, 1990; Maffulli et al, 2000; Matthew \& Moore, 1991). ACS-treated animals showed markedly more mature, thick reddish/orange collagen fibers at weeks 2 and 8 postoperatively as compared with controls and quantitative evaluation of collagen type III showed a three fold reduced level of this collagen at weeks 1,2 and 8. This finding is in agreement with the reports of Aspenberg and Virchenko who documented a beneficial effect of platelet concentrate administration on the histological appearance of the healing tendon, with a concomitant increased tendon callus strength and stiffness by about $30 \%$ after week 1 , an improvement which persisted for as long as 3 weeks after the injection (Aspenberg \& Virchenko, 2004; Wright-Carpenter et al2004). Despite the improved collagen synthesis, which is apparent from the significantly greater tendon thickness at weeks 1,4 and 8 , stiffness was significantly $(\mathrm{P}=0.038)$ increased at week 4 .

In summary, it is clearly evident that ACS injections accelerate the rate of organization of repair tendon tissue. ACS injections apparently do not critically limit inflammatory signals of the early healing phase but supplement critical growth factors that are present in serum in limiting concentrations. The biologically active components in ACS are responsible for the observed accelerated Achilles tendon healing (Majewski et al. 2009).

\subsection{Natural course of healing}

The normal course of tendon healing with an emphasis on growth factor expression has been studied for various models of tendon pathology, including rotatory cuff tears and Achilles tendon ruptures in a rat model as well as in tenocyte cultures. However only a few studies have focused on the expression of several growth factors over time. Indications as to which growth factors are at work at what time during tendon healing can be emerge from studies on the temporal growth factors expression during unaided healing as well as from studies on the effects of local growth factor administration. As to the unaided healing, Würgler-Hauri and coworkers documented the temporal expression of growth factors in tendon-to-bone healing in a rat supraspinatus model using immunohistochemical staining . Their results show that all growth factors measured increase at weeks 1 and 2, as well as at week 8 (Würgler-Hauri et al., 2007).

As tendons vary greatly in function and structure, we studied the expression during healing over time of bFGF, BMP-12, VEGF and TGF- $\beta$ in a rat Achilles tendon healing model. After surgically introduced, immunohistological analysis was performed for 1, 2, 4 and 8 weeks of healing. Results showed a high initial concentration of bFGF and BMP-12, which sank rapidly after 2 weeks, while VEGF remained elevated just slowly decreasing over time and TGF- $\beta$ even increased after 8 weeks. The observed difference compared to the rotatory cuff model is maybe due to tendon-to-tendon versus tendon-to-bone healing.

\section{Tissue engineering}

\subsection{Cytokines modulation}

Growth factors and cytokines modulate the differentiation of tendons during embryogenesis and play also an important role during the healing process of tendons (Grotendorst, 1988; Hudson-Goodman et al, 1990). In healthy canine flexor tendons an increased expression of 
bFGF was measured whereas the amount of PDGF was increased in healing tendons (Duffy et al, 1995). Under the influence of PDGF an increased chemotaxis of fibroblasts, proliferation rate and collagen synthesis was observed (Grotendorst, 1988; Pierce et al, 1995). bFGF caused an increased fibroblast proliferation in in vitro Achilles tendons and an angiogenic effect of bFGF has been shown (Chan, et al; 1997; Gabra et al, 1994). During tendon embryogenesis bone morphogenetic proteins (BMP), especially BMP 12 and 13 cause the expression of elastin and collagen I. In animal studies BMP 12 induced healing of the patellar tendon (Möller et al, 2000). In in vitro studies an increased mRNA expression of type I collagen by the transforming growth factor * family (TGF*) has been shown.

\subsection{Scaffolds}

Lately biocompatible and biodegradable scaffolds are also used in tissue engineering of tendon healing. They are thought to mimic native extracellular matrix in the beginning of tendon healing. Moreover scaffolds are supposed to hold cells that are involved in the tendon healing either by being implanted or chemo-attracted to the scaffold (Gott et al, 2011). Combination of scaffolds and tenocytes led to superior histologic and biomechanical repairs in flexor tendons compared to scaffolds without tenocytes. However, the use of scaffolds might impair tendon gliding within narrow synovial sheaths (Adams et al., 2006; Cao et al., 2002; Gott et al, 2011). The positive affect of scaffolds in Achilles tendon and rotator cuff repair is rather achieved by combination with other tissue engineering modalities e.g. growth factors or bio-adhesiv coat than by the structural support alone, which showed to be not sufficient enough. Pericardium or dermal tissue that was augmented with a bioadhesive coating showed improved biomechanical properties compered to control in an Achilles tendon model (Brodie et al., 2011; Derwin et al., 2006; Gott et al, 2011). In a rabbit model a polyglycolic-acid scaffold combined with fibrin was seeded with Achilles tenocytes and then implanted in a defined Achilles tendon defect. Compared to the control groups (scaffold alone and without scaffold) macroscopic and microscopic appearance was superior. Unfortunately no biomechanical testing was performed in this study (Stoll et al. 2011). In massive rotator cuff tear a functioning scaffold model is desirable. Nevertheless the goal remains to create a tension-free, anatomical repair that restores the footprint as scaffolds have not yet shown to have the adequate biomechanical power (Nho et al, 2010). In this field more research is need to be done. Rather the biologic part than the mechanic part seems to be promising in the use of scaffolds.

\subsection{Gene intervention}

Several investigators have studied gene transfer to tendons. Three model systems have been used; the patellar tendon of the knee (Gerich et al., 1996; Nakamura et al., 1996), the digital flexor tendon (Goomer et al. 2000, Lou et al., 1996, Lou et al., 1997, Lou et al., 2001), and the Achilles tendon (Dai et al., 2003). In these model systems, repair strength and gap formation of the tendon scar is important while with digital flexor tendons a second, equally important issue is adhesion formation between the healing tendon and the surrounding tendon pulley sheaths.

The investigators considered the feasibility of gene transfer in digital flexor tendons of chickens and dogs, and patellar or Achilles tendons of rats $[5,13,25,35]$. Nakamura, used the 
HVJ-liposome construct to deliver B-galactosidase to a rat patellar tendon [35]. Approximately $7 \%$ of the cells were $B$-galactosidase positive 7 days after injection and this decreased to $0.2 \%$ of cells 56 days after injection. [35]. Digital flexor tendons in dogs and chickens were modified using cationic liposomes and expression vector containing $\mathrm{B}$ galactosidase to enhance transfection $[13,25]$. 6 days later the transfection efficiencies were reported as $100 \%$ [13]. The authors reported no evidence of immune response.

The second digital flexor tendon model was that of chicken flexor tendons [25]. Bgalactosidase expression was detected in the tendon and tendon sheath at 3, 30 and 75 days after injection. An estimated $2-5 \%$ of cells were $ß$-galactosidase positive and most of these cells were on the surfaces of the tendon and tendon sheath [25]. The fourth study used a transected rat Achilles tendon model without suturing to evaluate B-galactosidase expression [5]. At 4 days after transection, recombinant adenovirus carrying LacZ was placed in the transection site. The authors detected B-galactosidase expression up to 17 days after injection and 21 days after transection. Transduction rates increased with higher doses of injected virus [5]. The previous four studies with tendons used direct injection of the vectors in or around the tendons.

Oezkan investigated the feasibility of intra-arterial injection of HVJ-liposomes for transfecting cells of the patellar tendon and found that between 8 and $12 \%$ of the cells positive [38].

Three studies have tried to manipulate the healing environment of tendons $[27,26,36]$. Two studies evaluated digital flexor tendons, studying adhesion formation and the tendon scar strength [26,27]. Lou, used gene intervention to manipulate the healing environment of chicken digital flexor tendons to investigate tendon adhesions [26].

Lou did a study in chicken digital flexor tendon. They used an adenoviral construct with BMP-12 to transduce primary chicken tendon cells in vitro. Collagen Type I synthesis was increased $30 \%$ by cells transduced with the adenoviral-BMP-12 construct when compared to control cells or cells transduced with an adenovirus-ß-galactosidase construct. While there were no significant differences in the ultimate failure force or the stiffness at 2 weeks, by 4 weeks these values for adenoviral-BMP-12 group were approximately significant greater than the values of adenoviral- $\$$-galactosidase group [27].

\section{How to best improve tendon healing with growth factors}

Tendon ruptures and tears are slow healing common injuries that are often treated surgically with unsatisfactory results for some patients. As the biology of the healing process and how it is influenced by growth factors become clear, one can consider introducing biological therapy into clinical use. As data on the effect of specific recombinant growth factors were mainly obtained from studies in different animal models of tendon healing, these are difficult to compare.

In our own studies we have compared the benefits of three different approaches of tendon healing influenced by growth factors: TGF- $\beta$ as an example for multifunctional growth factors inducing a wide range of cellular responses, BMP-12 as example for the specific induction of tendon and ligament tissue, and a growth factor cytokine mix derived from serum and activated platelets as an example for biological therapy. 
We hypothesized that the interplay of numerous growth factors and cytokines contributes to optimal tendon healing. We reasoned that the growth factors normally present in serum and released by activated platelets could approximate the growth factor/cytokine mix seen by the injured tendon better then when single growth factors are applied.

The transected rat Achilles tendon was used for the evaluation of the effect of all growth factors. Doing a pre-study, staining intensity for BMP-12, bFGF, TGF $\beta$, and VEGF showed that all these factors are highly expressed at the early stage of healing.

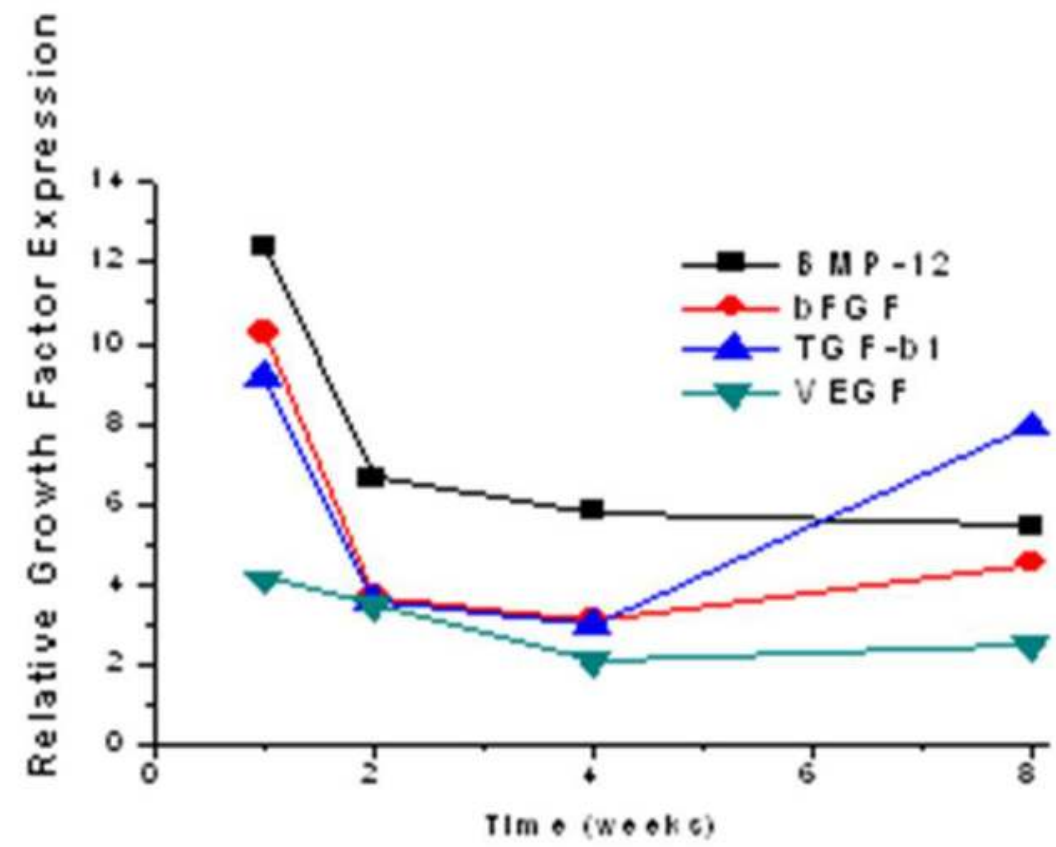

Fig. 1. Relative Growth factor Expression in correlation to the time after injury. A relative high expression was measured within the first week. TGF- $\beta$ tends to rise again after 4 weeks, whereas the others remain at a stable level after two weeks.

Therefore, BMP-12 cDNA, and separately TGF- $\beta$ cDNA were introduced at the time of surgery and activated serum (ACS) was injected at the time of tendon surgery as well as 24 and 48 postoperatively. Animals were sacrificed 1, 2, 4, and 8 weeks later and Achilles tendon tendon-bone units were collected. Biomechanical testing, histochemical and immunochemical analyses of regenerate sections were performed using standard techniques.

\subsection{Biomechanical testing}

TGF- $\beta$ : Biomechanical testing of the healing rat Achilles tendon showed an increased maximum load. The maximum failure load was significantly increased one week after surgery, compared to the control $(\mathrm{p}=0.0012)$, and was also somewhat higher after 4 and 8 weeks. Tendon stiffness was significantly higher after one week. 
BMP-12: Tendons exposed to BMP-12 showed significantly greater strength $(\mathrm{P}=0.0379)$ than controls at 1 week. Tendon stiffness was significantly higher at 1, 2 and 4 weeks Control tendons, in contrast, only achieved normal stiffness values after 8 weeks.

AS: AS-tendons reached stiffness values 4 weeks earlier than the controls. There were no differences in maximum load to failure between groups up to week 8 .

\subsection{Histology}

TGF- $\beta$ : Histological examination showed a much more organized and homogeneous pattern of collagen fibers over all time points compared to controls. The fibers grew to bigger bundles much earlier with a higher degree of collagen crimp.

BMP-12: The Histological examination was quite similar compared to TGF- $\beta$ group. However, after 8 weeks, there was one tendon with an enchondral ossification at the experimental group.

AS: Collagen fibers were apparent as early as week 1 postoperatively. These collagen fibers were visibly thicker and more bundled than in all other tendon at this stage. The trend toward better organized collagen continued in week 2 and 4 . At 8 weeks postoperatively, the tendons had a smooth appearance resembling very much normal tendons with small fibrocartilaginous areas in the center of the stress areas.

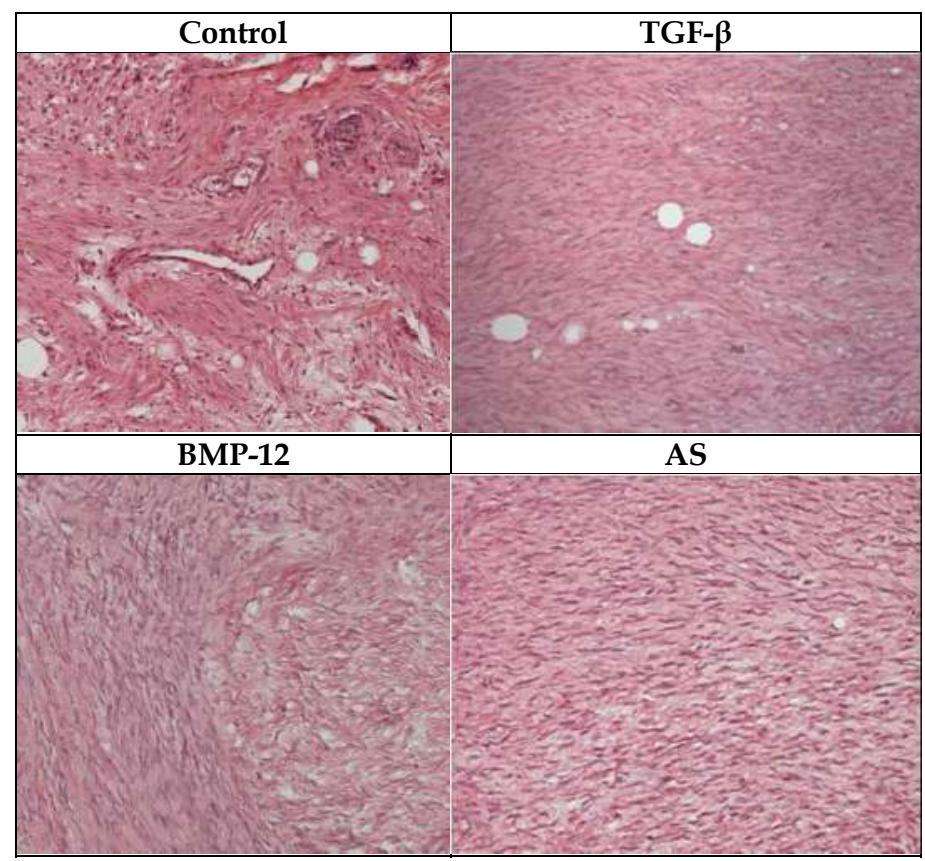

Fig. 2. Effect of different Growth Factor on the histologic appearance of the repair site.

Sections were made from tendons recovered 1 week after surgery and stained with hematoxylin and eosine. Magnification: x200. 


\subsection{Collagen}

Control tendons contain mainly collagen I, and approximately $3 \%$ collagen III. In regenerates formed under the influence of TGF- $\beta$ this collagen ratio is reached after 2 weeks. With BMP-12 stimulation a collagen III content of $3 \%$ is reached by week 4 , and with AS by week 8 .

\begin{tabular}{|c|c|c|c|}
\hline & Biomechanics & $\begin{array}{c}\text { Ratio collagen type } \\
\text { I/III }\end{array}$ & Histology \\
\hline TGF- $\beta$ & + & +++ & + \\
\hline BMP-12 & ++ & ++ & $+/(-)$ \\
\hline $\begin{array}{c}\text { Biological therapy } \\
\text { (ACS) }\end{array}$ & - & + & +++ \\
\hline
\end{tabular}

Table 3. Effects of growth-factors on transected rat Achilles tendon healing

\subsection{Conclusions}

Our data indicate that the mix of growth factors and cytokines in activated serum yields superior tendon healing than single growth factors as judged by histological appearance of the regenerate. However, growth factors BMP-12 and TGF- $\beta$ yielded better biomechanical results and more favorable collagen expression ratios, respectively. As tendon ruptures and tears are slow healing injuries, the quality of life and economic productivity of patients is often diminished for weeks. It would benefit patients greatly if the healing process could be accelerated and improved by biological intervention as appears possible from our data. At present it is not clear which of the approaches of growth factor delivery is most promising as each of them yields better outcomes in a respect or another (collagen ratio, histological appearance, biomechanical properties). Further studies are needed to determine whether it is possible to obtain normal tendon tissue by growth factor application.

\section{Abbreviations}

$\begin{array}{ll}\text { ACS } & \begin{array}{l}\text { autologous conditioned serum } \\ \text { bFGF }\end{array} \\ \text { basic fibroblast growth factor } \\ \text { bone morphogenetic protein }\end{array}$




\section{References}

Adams JE, Zobitz ME, Reach JS, Jr, An KN, Steinmann SP. Rotator cuff repair using an acellular dermal matrix graft: an in vivo study in a canine model. Arthroscopy 22:700-709, 2006.

Aspenberg P, Virchenko O. Platelet concentrate injection improves Achilles tendon repair in rats. Acta Orthop Scand 2004;75:93-99

Birk, O.E., \& Trelstad R.L. (1984). Extracellular compartments in matrix morphogenesis: Collagen fibril, bundle and lamellar formation by corneal fibroblasts. J Cell Biol, Vol. 99, No. 6 (December 1984), 2024-2033, ISSN: 0021-9533

Bos PK, van Osch G, Frenz DA, et al. Growth factor expression in cartilage wound healing: temporal and spatial immunolocal- ization in a rabbit auricular cartilage wound model. Osteoarthritis Cartilage 2001; 9 (4): 382-9

Bosch G, van Schie HT, de Groot MW, Cadby JA, van de Lest CH, Barneveld A, van Weeren PR. Effects of platelet-rich plasma on the quality of repair of mechanically induced core lesions in equine superficial digital flexor tendons: A placebo-controlled experimental study. J Orthop Res 2010, Feb;28(2):211-7

Cao Y, Liu Y, Liu W, Shan Q, Buonocore SD, Cui L. Bridging tendon defects using autologous tenocyte engineered tendon in a hen model. Plast Reconstr Surg 110:1280-1289, 2002

Chan BP. Chan KM, Mafulli N (1997) Effect of basic fibroblast growth factor: an in vitra study of tendon healing. Clin Orthop 342: 239-247

Chan KM, Fu SC, Wong YP, Hui WC, Cheuk YC, and Wong MW.Expression of transforming growth factor beta isoforms and their roles in tendon healing. Wound Repair Regen, 16(3):399-407, May-Jun 2008

Coombs RHR, Klenerman L. Narcisi p. Nichols A, Pope FM (1980) Collagen typing in Achilles tendon rupture. J Bone Joint Surg Br 62: 258

Dai Q, Manfield L, Wang Y, Murrell GAC (2003) Adenovirus-mediated gene transfer to healing tendon - enhanced efficiency using a gelantin sponge. J Orthop Res 21: 604609

Derwin KA, Baker AR, Spragg RK, Leigh DR, Iannotti JP. Commercial extracellular matrix scaffolds for rotator cuff tendon repair. Biomechanical, biochemical, and cellular properties. J Bone Joint Surg 88:2665-2672, 2006

De Vos RJ, Weir A, van Schie HT, Bierma-Zeinstra SM, Verhaar JA, Weinans H, Tol JL. Platelet-rich plasma injection for chronic Achilles tendinopathy: a randomized controlled trial. JAMA. 2010; 303:144-9

Ducy P, Karsenty G. (2000) The family of bone morphogenetic proteins. Kidney Int. 57:22072214

Duffy FJ, Seiler JG, Gelberman RH, Hergrueter CA. Growth factors and canine flexor tendon healing: Initial studies in uninjured and repair models. J Hand Surg Am 1995, Jul;20(4):645-9

Edwall D, Schalling M, Jennische E, et al. Induction of insulin- like growth factor I messenger ribonucleic acid during regener- ation of rat skeletal muscle. Endocrinology 1989; 124: 820-5

Eliasson P, Fahlgren A, and Aspenberg P. Mechanical load and bmp signaling during tendon repair: a role for follistatin? Clin Orthop Relat Res, 466(7):1592- 1597, Jul 2008 
Eliasson P, Andersson T, and Aspenberg P. Rat achilles tendon healing: mechanical loading and gene expression. J Appl Physiol, 107(2):399-407, Aug 2009

Enzura Y, Rosen V, Nifuji A (1996) Introduction of hypertrophy in healing patellar tendon by implantation of human recombinant BMP 12. J Bone Min Res 11: 401

Forslund C, Rueger D, and Aspenberg P. A comparative dose-response study of cartilagederived morphogenetic protein (cdmp)-1, -2 and -3 for tendon healing in rats. J Orthop Res, 21(4):617-621, Jul 2003.

Fortier LA, Balkman C, Sandell LJ, et al. Insulin-like growth factor-I gene expression patterns during spontaneous repair of acute articular cartilage injury. J Orthop Res 2001; 19 (4): 720-8

Fufa D, Shealy B, Jacobson M, Kevy S, Murray MM. Activation of platelet-rich plasma using soluble type I collagen. J Oral Maxillofac Surg. 2008; 66:684-90

Gabra N, Khiat A, Calabres (1994) Detection of elevated basic fibroblast growth lactat during early hours of in vitra angiogenesis using a fast ElISA immunoassay. Biochem Biophys Res Commun 205:1423-1430

Gerich TG, Kang R, Fu FH, Robbins PD, Evans CH (1996) Gene transfer to rabbit patellar tendon: potential for genetic enhancement of tendon and ligament healing. Gene Ther 3: 1089-1093

Goomer RS, Maris TM, Gelberman R, Boyer M, Silvia M, Amiel D (2000) Nonviral in vivo gene therapy for tissue engenieering of articular cartilage and tendon repair. Clin Orthop Relat Res. 379 Suppl: 189-200

Gott M, Ast M, Lane LB, Schwartz JA, Catanzano A, Razzano P, Grande DA. Tendon phenotype should dictate tissue engineering modality in tendon repair: a review. Discov Med. 2011 Jul;12(62):75-84

Grotendorst GR, Martin GR, Pencer D (1985) Stimulation of granulation tissue forma- tion by PDGF in normal and diabetic rats. J Clin Invest 76: 2323-2329

Grotendorst GR (1988) Growth factors as regulators of wound repair. Int Tissue React 10: 337-344

Hefti F, Stoll TM. (1995) Healing of ligaments and tendons. Orthopade. 24:237-45

Hildebrand KA, Woo SL, Smith DW, et al. The effects of platelet-derived growth factor-BB on healing of the rabbit medial collateral ligament: an in vivo study. Am J Sports Med 1998; 26 (4): 549-54

Hou Y, Mao Z, Wei X, Lin L, Chen L, Wang H, Fu X, Zhang J,and Yu C.Effects of transforming growth factor-beta1 and vascular endothelial growth factor 165 gene transfer on achilles tendon healing. Matrix Biol, 28(6):324-335, Jul 2009.

Hudson-Goodman P, Girard N, Jones MB (1990) Wound repair and the potential use of growth factors. Heart Lung 19: 379-384

James, R., Kesturu, G., Balian, G. \& Chhabra, A.B. Tendon: biology, biomechanics, repair, growth factors, and evolving treatment options. J Hand Surg Am 33, 102-12 (2008)

Janqueira LC, Bignolas G, Brentani RR (1978) Picrosirus staining plus polarization microscopy, a specific method for collagen detection in tissue sections. Histochemical Journal 11: 447-455

Jorgensen HG, McLellan SD, Crossan JF, and Curtis AS. Neutralisation of tgf beta or binding of vla-4 to fibronectin prevents rat tendon adhesion following transection. Cytokine, 30(4):195-202, May 2005. 
Jozsa L, Kannus P, Reffy A, Demel Z (1984) Fine structural alterations of collagen bets in degenerative tendinopathy. Arch Orthop Trauma Surg 103: 47-51

Jozsa L, Reffy A, Kannus P, Demel S, Elek E. Pathological alterations in human tendons. Arch Orthop Trauma Surg 1990;110:15-21

Kashiwagi K, Mochizuki Y, Yasunaga Y, Ishida O, Deie M, and Ochi M. Effects of transforming growth factor-beta 1 on the early stages of healing of the achilles tendon in a rat model. Scand J Plast Reconstr Surg Hand Surg, 38(4):193-197, 2004.

Kurtz CA, Loebig TG, Anderson DD, DeMeo PJ, Campbell PG. Insulin-like growth factor I accelerates functional recovery from Achilles tendon injury in a rat model. Am J Sports Med 1999;27:363-369.

Laemmli UK (1970) Cleavage of structural proteins during assembly of the head of bacteriophage T4. Nature 227:680-685

Lou J, Manske PR, Aoki M, Joyce ME (1996) Adenovirus-mediated gene transfer into tendon and tendon sheath. J Orthop Res 14: 513-517

Lou J, Kubota H, Hotokezaka S, Ludwig FJ, Manske PR (1997) In vivo gene transfer and overexpression of focal adheasion kinase (pp125FAK) mediated by recombinant adenovirus-induced tendon adheasion formation and epitenon cell change. J Orthop Res 15: 911-918

Lou J, Tu Y, Burns M, Silva MJ, Manske P: BMP-12 gene transfer augmentation of lacerated tendon repair. J Orthop Res 19:1199-1202, 2001

Lui PP, Cheuk YC, Hung LK, Fu SC, and Chan KM. Increased apoptosis at the late stage of tendon healing. Wound Repair Regen, 15(5):702-707, Sep-Oct 2007.

Lynch SE, Colvin R, Antoniades HN. Growth factors in wound healing: single and synergistic effects on partial thickness porcine skin wounds. J Clin Invest 1989; 84 (2): $640-6$

Maffulli N, Ewen SW, Waterston SW, et al. (2000) Tenocytes from ruptured and tendinopathic achilles tendons produce greater quantities of type III collagen than tenocytes from normal achilles tendons. An in vitro model of human tendon healing. Am J Sports Med: 499-505

Maffulli N, Moller HD, Evans CH (2002) Tendon healing: can it be optimised? Br J Sports Med 36:315-316

Majewski M, Betz O, Ochsner PE, Liu F, Porter RM, and Evans CH. Ex vivo adenoviral transfer of bone morphogenetic protein 12 (bmp-12) cdna improves achilles tendon healing in a rat model. Gene Ther, 15(16):1139-1146, Aug 2008.

Majewski M, Ochsner PE, Liu F, Flückiger R, Evans $\mathrm{CH}$. Accelerated healing of the rat Achilles tendon in response to autologous conditioned serum. Am J Sports Med. 2009 Nov;37(11):2117-25.

Mason ML, Allen HS (1941) The rate of healing of tendons: an experimental study of tensile strength. Ann Surg 113: 424-459

Matthew CA, Moore MJ. Regeneration of rat extensor digitorum longus tendon: the effect of a sequential partial tenotomy on collagen fibril formation. Matrix 1991;11:259-268

Möller HD, Evans CD, Robins PD, Fu FH (1998) Gene therapy in orthopaedic sports medizine. In: Chan KM, Fu FH, Kurosaka M, Mafulli N, Rolf C, Liu 5 (eds) Controversies in ortho- paedic sports medicine. Williams-Wilkins, Hong Kong, pp 577-588 
Möller HD, Evans CH, Maffulli N. Aktuelle aspekte der sehnenheilung. Der Orthopäde 2000;29(3):182-7

Molloy, T.; Wang Y., \& Murrell, G. (2003). The roles of growth factors in tendon and ligament healing. Sports Med, Vol 33:381-394.

Murray DH, Kubiak EN, Jazrawi LM, Araghi A, Kummer F, Loebenberg MI, and Zuckerman JD. The effect of cartilage-derived morphogenetic protein 2 on initial healing of a rotator cuff defect in a rat model. J Shoulder Elbow Surg, 16(2):251-254, Mar-Apr 2007

Nakamura N, Horibe S, Matsumoto N, Tomita T, Natsuume T, Kaneda Y, Shino K, Ochi T (1996) Transient introduction of a foreign gene info healing rat patellar ligament. J Clin Invest 97: 226-231

Nakamura N, Shino K, Natsuume T, Horibe S, Matsumoto N, Kaneda Y, Ochi T (1998) Early biological effect of in vivo gene transfer of platelet-derived growth factor (PDGF)-B into healing patellar ligament. Gene Therapy 5:1165-1170

Nho SJ, Delos D, Yadav H, Pensak M, Romeo AA, Warren RF, MacGillivray JD. Biomechanical and biologic augmentation for the treatment of massive rotator cuff tears.Am J Sports Med. 2010 Mar;38(3):619-29. Epub 2009 Sep 23.

O'Brien T (1992) Functional anatomy and physiology of tendons. Clin Sports Med 11: 505520

Özkan I, Shino K, Nakamura N , Natsuume T, Matsumoto N, Horibe S, Tomita T, Kaneda Y, Ochi T (1999) Direct in vivo gene transfer to healing rat patellar tendon by intraarterial delivery of haemaggglutinating virus of Japan Liposomes. Trans Orthop Res Soc 29: 63-67

Party DAD, Barnes GRG, Craig AS (1978) A comparison of the size distribution of collagen fibrils in connective tissues as a function of age and a possible relationship between fibril size distribution and mechanical properties. Proc Roy Soc London 203: 305321

Petersen W, Pufe T, Zantop T, Tillmann B, Mentlein R. (2003) Hypoxia and PDGF have a synergistic effect that increases the expression of the angiogenetic peptide vascular endothelial growth factor in Achilles tendon fibroblasts. Arch Orthop Trauma Surg.123: 485-488

Petersen W, Pufe T, Unterhauser F, Zantop T, Mentlein T, and Weiler A. The splice variants 120 and 164 of the angiogenic peptide vascular endothelial cell growth factor (vegf) are expressed during achilles tendon healing. Arch Orthop Trauma Surg, 123(9):475-480, Nov 2003

Petersen W, Varoga D, Zantop T, Hassenpflug J, Mentlein R, Pufe T. (2004) Cyclic strain influences the expression of the vascular endothelial growth factor (VEGF) and the hypoxia inducible factor 1 alpha (HIF-1alpha) in tendon fibroblasts. J Orthop Res. 22:847-853

Pierce GF, Mustoe T, Lingelbach J, et al. Platelet-derived growth factor and transforming growth factor-beta enhance tissue repair activities by unique mechanisms. J Cell Biol 1989; 109 (1): 429-40

Pierce GF, Tarpley JE, Tseng J (1995) Detection of platelet-derived growth factor (PDGF)- IW in actively healing human wounds treated with recombinant PDGF-pp and absence of PDGF in chronic nonhealing wounds. J Clin Invest 96: 1336-1350 
Pufe T, Petersen W, Kurz B, Tsokos M, Tillmann B, and Mentlein R. Mechan- ical factors influence the expression of endostatin-an inhibitor of angiogenesis-in tendons. J Orthop Res, 21(4):610-616, Jul 2003.

Rodeo SA, Delos D, Weber A, Ju X, Cunningham ME, Fortier L, Maher S. What's New in Orthopaedic Research. J Bone Joint Surg Am. 2010; 92:2491-2501

Roberts AB, Flanders KC, Kondaiah P, Thompson NL, Obberghen-Schilling E, Wakefield L, Rossi P, de Crombrugghe B, Heine U, Sporn MB: Transforming growth factor beta: biochemistry and roles in embryogenesis, tissue repair and remodeling, and carcinogenesis. Recent Prog Horm Res 44:157-197, 1988

Ronnstrand L, Heldin C. Mechanisms of platelet-derived growth factor-induced chemotaxis. Int J Cancer 2001; 91 (6): 757-62

Rubini M, Werner H, Gandini E, et al. Platelet-derived growth factor increases the activity of the promoter of the insulin-like growth factor-I (IGFI) receptor gene. Exp Cell Res 1994; 211: 374-9

Sahoo S, Toh SL, and Goh JC. A bfgf-releasing silk/plga-based biohybrid scaffold for ligament/tendon tissue engineering using mesenchymal progenitor cells. Biomaterials, 31(11):2990-2998, Apr 2010.

Sciore P, Boykiw R, Hart DA. Semi-quantitive reverse trans- criptase polymerase chain reaction analysis of mRNA for growth factors and growth factor receptors from normal and healing rabbit medial collateral ligament tissue. J Orthop Res 1998; 16: 429-37

Stoll C, John T, Conrad C, Lohan A, Hondke S, Ertel W, Kaps C, Endres M, Sittinger M, Ringe J, Schulze-Tanzil G. Healing parameters in a rabbit partial tendon defect following tenocyte/biomaterial implantation. Biomaterials. 2011 Jul;32(21):4806-15. Epub 2011 Apr 6.

Tsuzaki M, Brigman BE, Yamamoto J, Lawrence WT, Simmons JG, Mohapatra NK, et al. Insulin-like growth factor-I is expressed by avian flexor tendon cells. J Orthop Res 2000;18:546-556.

Thomopoulos S, Das R, Sakiyama-Elbert S, Silva MJ, Charlton N, and Gelberman RH. bfgf and pdgf-bb for tendon repair: controlled release and biologic activity by tendon fibroblasts in vitro. Ann Biomed Eng, 38(2):225-234, Feb 2010.

Tsuzaki M, Brigman B, Yamamoto J, et al. Insulin-like growth factor-I is expressed by avian flexor tendon cells. J Orthop Res 2000; 18 (4): 546-56

Vogt PM, Lehnhardt M, Wagner D, et al. Growth factors and insulin-like growth factor binding proteins in acute wound fluid. Growth Horm IGF Res 1998; 8 Suppl B: 1079

Wolfman NM, Hattersley G, Cox K, Celeste AJ, Nelson R, Yamaji N, Dube JL, DiBlasioSmith E, Nove J, Song JJ, Wozney JM, Rosen V: Ectopic induction of tendon and ligament in rats by growth and differentiation factors 5,6 , and 7 , members of the TGF-beta gene family. J Clin Invest 100:321-330, 1997

Wozney JM, Rosen V: Bone morphogenetic protein and bone morphogenetic protein gene family in bone formation and repair. Clin Orthop Relat Res26-37, 1998

Wright-Carpenter T, Opolon P, Appell HJ, Meijer H, Wehling P, Mir LM. Treatment of muscle injuries by local administration of autologous conditioned serum: animal experiments using a muscle contusion model. Int J Sports Med 2004;25:582-587 
Würgler-Hauri CC, Dourte LM, Baradet TC, Williams GR, and Soslowsky LJ. Temporal expression of 8 growth factors in tendon-to-bone healing in a rat supraspinatus model. J Shoulder Elbow Surg, 16(5 Suppl):198-203, Sep-Oct 2007

Yoshikawa Y, Abrahamsson S. Dose-related cellular effects of platelet-derived growth factor-BB differ in various types of rabbit tendons in vitro. Acta Orthop Scand 2001; 72 (3): 287-92

Zhang F, Liu H, Stile F, Lei M P, Pang Y, Oswald T M, Beck J, Dorsett-Martin W, and Lineaweaver W C. Effect of vascular endothelial growth factor on rat achilles tendon healing. Plast Reconstr Surg, 112(6):1613-1619, Nov 2003. 


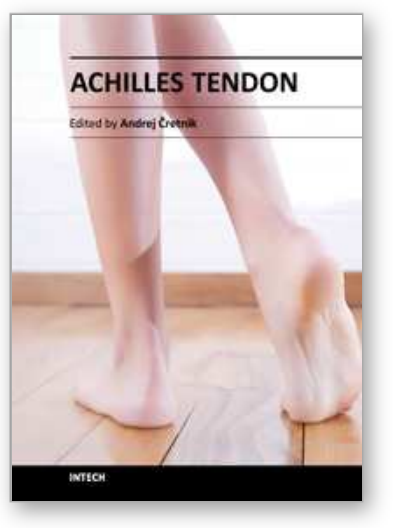

\author{
Achilles Tendon \\ Edited by Prof. Andrej Cretnik
}

ISBN 978-953-51-0264-9

Hard cover, 144 pages

Publisher InTech

Published online 08, January, 2012

Published in print edition January, 2012

Achilles tendon has always attracted a great attention. Its disorders include various problems from pain and swelling with bumps to functional impairment or even ruptures. Debates concerning aetiology and optimal treatment are still going on. A lot of efforts and research have already been put on to find the answers to unsolved problems and this book is an attempt to share (some of) these findings to the readers. If only one of the papers helps the therapists or patients in understanding and solving their problems, we will consider that the mission of the book was accomplished.

\title{
How to reference
}

In order to correctly reference this scholarly work, feel free to copy and paste the following:

Sebastian Müller, Atanas Todorov, Patricia Heisterbach and Martin Majewski (2012). Tendon Healing with Growth Factors, Achilles Tendon, Prof. Andrej Cretnik (Ed.), ISBN: 978-953-51-0264-9, InTech, Available from: http://www.intechopen.com/books/achilles-tendon/how-to-best-improve-tendon-healing-with-growth-factors

\section{INTECH}

open science | open minds

\section{InTech Europe}

University Campus STeP Ri

Slavka Krautzeka 83/A

51000 Rijeka, Croatia

Phone: +385 (51) 770447

Fax: +385 (51) 686166

www.intechopen.com

\section{InTech China}

Unit 405, Office Block, Hotel Equatorial Shanghai

No.65, Yan An Road (West), Shanghai, 200040, China 中国上海市延安西路65号上海国际贵都大饭店办公楼 405 单元

Phone: $+86-21-62489820$

Fax: +86-21-62489821 
(C) 2012 The Author(s). Licensee IntechOpen. This is an open access article distributed under the terms of the Creative Commons Attribution 3.0 License, which permits unrestricted use, distribution, and reproduction in any medium, provided the original work is properly cited. 